\title{
Recurrent Olfactory Neuroblastoma
}

National Cancer Institute

\section{Source}

National Cancer Institute. Recurrent Olfactory Neuroblastoma. NCI Thesaurus. Code C115384.

The reemergence of olfactory neuroblastoma after a period of remission. 